\title{
Contribuições do círculo de cultura à participação popular na gestão da educação básica: diálogos com Paulo Freire
}

\author{
Contributions of the culture circle to popular participation in the management \\ of basic education: dialogues with Paulo Freire \\ Contribuciones del círculo de cultura a la participación popular en la gestión de \\ la educación básica: diálogos con Paulo Freire
}

\author{
NILTON BRUNO TOMELIN \\ https://orcid.org/0000-0001-5501-5961 \\ Universidade Regional de Blumenau \\ Programa de Pós Graduação em Educação \\ Departamento de Educação \\ Blumenau, SC, Brasil \\ RITA BUZZI RAUSCH \\ https://orcid.org/0000-0002-9413-4848 \\ Universidade Regional de Blumenau \\ Programa de Pós Graduação em Educação \\ Departamento de Educação \\ Blumenau, SC, Brasil
}

\begin{abstract}
Resumo: A presente investigação tem como objetivo identificar possíveis contribuições do Círculo de Cultura à participação popular na gestão da educação básica numa perspectiva democrática. Trata-se de uma pesquisa teórica fundamentada no pensamento de Paulo Freire. O estudo sinaliza que uma gestão democrática na educação básica, nesta perspectiva, implica em assumir valores, como comunhão, iniciativa, reciprocidade, comprometimento e solidariedade. Desta forma o Círculo de Cultura é uma alternativa possível à educação popular e ao protagonismo da participação popular na sociedade.
\end{abstract}

Palavras-chave: Círculo de Cultura. Gestão democrática. Paulo Freire. Participação popular. Educação popular.

Abstract: The present investigation aims to identify possible contributions of the Culture Circle to popular participation in the management of basic education in a democratic perspective. This is a theoretical research based on the theory of Paulo Freire. The study indicates that democratic management in basic education, in this perspective, implies assuming values such as communion, initiative, reciprocity, commitment, and solidarity. In this regard, the Culture Circle is a possible alternative to popular education and the role of popular participation in society.

Keywords: Culture Circle. Democratic management. Paulo Freire. Popular participation. Popular education. 
Resumen: La investigación presente tiene como objetivo identificar posibles aportes del Círculo de Cultura a la participación popular en la gestión de la educación básica desde una perspectiva democrática. Se trata de una investigación teórica basada en el pensamiento de Paulo Freire. El estudio indica que la gestión democrática en la educación básica, en esta perspectiva, implica asumir valores como comunión, iniciativa, reciprocidad, compromiso y solidaridad. Así, el Círculo de Cultura es una posible alternativa a la educación popular y al protagonismo de la participación popular en la sociedad.

Palabras clave: Circulo de Cultura. Gestión democrática. Paulo Freire. Participación popular. Educación popular.

\section{INTRODUÇÃO}

O desafio de fazer gestão na educação básica, em escolas públicas, requer um exercício consciente e crítico de mobilização coletiva em favor de objetivos e metas que nasçam dela. Para tanto, o coletivo necessita impregnar-se de um sentimento de pertencimento, por meio da participação efetiva em todos os momentos do processo de gestão. É improvável que essa participação, bem como a composição deste coletivo, ocorram de forma espontânea, mas também não podem ser fruto de algum tipo de imposição, coerção ou constrangimento. Não sendo fruto de espontaneísmo e não podendo ser o cumprimento de uma obrigação, é preciso estabelecer um caminho para formar um coletivo que se proponha a materializar a participação no processo de gestão escolar.

Considerando esta demanda, Paulo Freire certamente é um autor (e também ator) que merecer ser ouvido. Sua autoria, e no que diz respeito à gestão, não é diferente, assenta-se na prática e na sensibilidade de perceber e acolher o outro como possibilidade concreta para uma nova forma de ser e de existir. Nesta perspectiva, cabe perguntar: quais as contribuições do Círculo de Cultura à participação popular na gestão democrática da educação básica? O objetivo desta investigação é identificar possíveis contribuições do Círculo de Cultura à participação popular na gestão da educação básica em uma perspectiva democrática.

Trata-se de uma pesquisa teórica, assentada na ideia de que é "dedicada a reconstruir teoria, conceitos, ideias, ideologias, polêmicas, tendo em vista, em termos imediatos, aprimorar fundamentos teóricos" (DEMO, 2000, p. 20). A reconstrução e o aprimoramento se referem, especialmente, à concepção de participação popular num processo democrático de gestão escolar. "A pesquisa teórica não implica imediata intervenção na realidade, mas nem por isso deixa de ser importante, pois seu papel é decisivo na criação de condições para a intervenção" (BAFFI, 2016, p. 01). Isto atende a consequência deste estudo que, identificando as contribuições do Círculo de Cultura à participação popular na 
gestão democrática da escola, poderá inspirar necessárias mudanças na gestão. Para tratar desta temática, o referencial teórico será Freire (2018; 2011; 2002; 2001; 1997; 1996; 1987; 1963), Freire e Betto (1985), Freire e Schor (1997) e Freire e Nogueira (2011), além de documentos da Secretaria Municipal de Educação de São Paulo (1989; 1990).

Em um primeiro momento, o texto sinaliza o conceito de participação popular para um contexto de gestão escolar democrática, visto que não há, efetivamente, uma única forma de descrevê-la. É fundamental debruçar-se sobre o entendimento acerca de que participação popular se deseja para a gestão da escola para que, em um momento seguinte, se estabeleça a possibilidade de inserila, como Freire fez enquanto Secretário Municipal de Educação da cidade de São Paulo. Finalmente, o texto propõe uma discussão sobre o Círculo de Cultura, como estratégia para que a experiência de Freire possa servir de encorajamento a outras possibilidades.

\section{PARTICIPAÇÃO POPULAR E DEMOCRACIA}

A democracia, independentemente do contexto em que se queira aplicá-la, está diretamente associada à participação do coletivo presente naquele contexto. Ocorre que esta participação pode se dar de diferentes formas e com intensidades diversas. Desta forma, num primeiro momento, é fundamental compreender de que participação popular se está tratando, para que seja possível oferecer a ela possibilidades de efetivação. Sabe-se que uma democracia parte do pressuposto de que os que assumem a função de liderança sejam legitimados pela aprovação (por sufrágio universal) da maioria e sua finalidade será tutelar a liberdade do coletivo. Mas é preciso atentar, também, para a necessidade de que a liberdade das lideranças seja limitada pela presença constante dos liderados no processo decisório. É nesta perspectiva que se tem a participação popular como característica fundante da democracia que se quer para uma gestão democrática da escola. Neste sentido é importante destacar que:

O mundo não é. O mundo está sendo. Como subjetividade curiosa, inteligente, interferidora na objetividade com que dialeticamente me relaciono, meu papel no mundo não é só o de quem constata o que ocorre, mas também o de quem intervém como sujeito de ocorrências. Não sou apenas objeto da história, mas seu sujeito igualmente. No mundo da história, da cultura, da política, constato não para me adaptar, mas para mudar (FREIRE, 2002, p. 85-86). 
Assim, define-se, claramente, que a participação dos sujeitos nos diferentes processos será de profunda autoria, agindo e promovendo a mudança que se espera. Portanto, a democracia de que trata este estudo não é um mero referendo a um projeto, mas a garantia de uma participação constante na sua construção e materialização. Entretanto, obviamente, para sustentar essa garantia há obstáculos historicamente constituídos e que apontam para grandes desafios, especialmente porque o modelo que se tem de democracia participativa impõe limites à liberdade da participação popular, ao mesmo tempo em que estende essa liberdade aos que lideram. Por isso

[...] é impossível atravessar a estrada do aprendizado da democracia, de como fazer democracia sem confrontar basismo e elitismo, expressões vivas em nossas tradições autoritárias. E nós estamos ainda no processo de aprender como fazer democracia. E a luta por ela passa pela luta contra todo tipo de autoritarismo (FREIRE, 2001, p. 136).

Neste sentido, é preciso reconhecer que a participação popular em um processo decisório, mesmo em nível escolar, não será fruto de uma concessão, mas de uma luta que fatalmente encontrará forte oposição pelas características do próprio contexto. $\mathrm{O}$ autoritarismo que se espraia pela sociedade, por certo, não se ausenta da escola, mas, ao contrário, além de estar nela, é potencializado por ela, quando educandos e educandas são submetidos a regras impostas, não construídas coletivamente, ou quando a sua participação nos processos decisórios é apenas para fins de referendo.

Freire (1996), falando de sua experiência como Secretário de Educação da cidade de São Paulo, entre 1989 e 1991, afirma que não era possível estabelecer um cenário democrático sem que houvesse um confronto com a tradição autoritária brasileira. Ao contrário, era necessário dar voz aos alunos e professores e diminuir o poder dos diretores. Por isso, segundo ele, foi necessário criar os Conselhos de Escola, para que também as famílias pudessem participar da construção do destino da escola de seus filhos. Trata-se de um poder colegiado, que, em suas palavras, limita o poder próprio secretário.

A gestão, nesta perspectiva, guarda forte relação com a concepção de educação popular, que, essencialmente, caracteriza-se pela preocupação em oferecer uma formação condizente com a realidade experienciada por cada coletivo. Parte desta vivência passa pela experiência democrática do contexto escolar, vivida por Paulo Freire e, por este motivo, é preciso ressaltar: 
Entendo a educação popular como o esforço de mobilização, organização e capacitação das classes populares; capacitação cientifica e técnica. Entendo que esse esforço não se esquece, que é preciso poder, ou seja, é preciso transformar essa organização do poder burguês que está aí, para que possa fazer escola de outro jeito. Em uma primeira 'definição' eu a aprendo desse jeito. Há estreita relação entre escola e vida política (FREIRE; NOGUEIRA, 2011, p. 33).

Dessa forma, é possível dizer que a participação popular no contexto da gestão da educação básica é também um exercício pedagógico, de formação humana. Práticas de ruptura ocorridas no contexto da escola podem constituir sujeitos autores de outras rupturas, nos diferentes cenários instituídos na sociedade. A participação popular, portanto, é uma convocação para uma forte insurgência em contraponto ao poder burguês, caracterizado por certo autoritarismo, geralmente excludente. Uma escola que tenha um rosto popular e constituído pela participação, que não admite exclusão, dos que efetivamente têm nela seu grande e, por vezes, único refúgio. Para que se compreenda melhor o sentido de participação popular, é fundamental compreender o sentido deste adjetivo. Assim,

[...] o adjetivo 'popular' refere-se ao povo e não à elite. Povo no sentido mais amplo, não tem nada a ver com as classes dominantes. Quando dizemos povo não estamos incluindo neste conceito os industriais e eu não quero dizer que os industriais não fazem parte de uma outra compreensão do conceito de povo, de povo de um país. Eu não tenho o poder de separá-los como eles fazem conosco. Mas de um ponto de vista sociológico e político, eles obviamente não são povo (FREIRE, 2018, p. 207, grifos no original).

Portanto, a participação popular implica numa lógica em que a democracia não se vê completa, pelo simples fato de o coletivo ser consultado ocasionalmente, ao contrário, se dará pela presença concreta deste coletivo em todos os momentos do processo de gestão. No contexto da escola, essa presença implica numa aprendizagem que servirá de inspiração para a atuação dos sujeitos deste coletivo, em outros contextos. O coletivo popular a que nos referimos, é constituído pelos que, convencionalmente, permanecem à margem dos processos decisórios, simplesmente sentindo suas consequências.

Mas não basta estabelecer este entendimento sem que se sinalize uma possibilidade concreta de como fazer. A diversidade de opiniões, vozes e experiências ecoarão na medida em que houver um instrumento que as respeite e as faça interagir, de maneira a construir um projeto de gestão que, efetivamente, represente o coletivo e suas relações. Neste sentido, ao assumir a Secretaria 
Municipal de Educação da cidade São Paulo, Freire estabelecer uma relação concreta entre o discurso em favor de uma gestão democrática da escola, por meio da participação popular e sua concreta materialização.

\section{GESTÃO DEMOCRÁTICA COM PARTICIPAÇÃO POPULAR}

A defesa de uma gestão democrática, com uma efetiva participação popular na sua implementação, teve, em Paulo Freire, não apenas um mentor teórico, mas um efetivo e comprometido idealizador. Para compreender esta relação, o pensamento e o que fazer de Paulo Freire em acerca do tema, é imprescindível considerar alguns aspectos de sua gestão frente à Secretaria Municipal de Educação da cidade de São Paulo.

Já nos primeiros momentos de sua gestão, escancarou seu propósito de tornar a gestão um processo amplamente participativo, como se pode ver em sua carta de apresentação, enviada pela Secretaria Municipal de Educação de São Paulo, intitulada "Aos que fazem a educação conosco em São Paulo", em que afirma que:

Assim que aceitei o convite que me fez a prefeita Luiza Erundina para assumir a Secretaria de Educação da Cidade de São Paulo pensei em escrever aos educadores, tão assiduamente quanto possível, cartas informais que pudessem provocar um diálogo entre nós sobre questões próprias de nossa atividade educativa. Não que tivesse em mente substituir, com as cartas os encontros diretos que pretendo realizar com vocês, mas porque pensava em ter nelas um meio a mais de viver a comunicação entre nós. Pensei, também, que as cartas não deveriam ser escritas só por mim. Educadoras e Educadores outros seriam convidados a participar desta experiência que pode constituir-se num momento importante da formação permanente do educador. O fundamental é que as cartas não sejam apenas recebidas e lidas, mas discutidas, estudadas e, sempre que possível, respondidas. Hoje tenho a satisfação de fazer chegar às mãos dos educadores da nossa rede um primeiro texto redigido por equipe deste Gabinete: "Construindo a Educação Pública Popular" - texto em que se fala um pouco de alguns pontos centrais do trabalho comum a ser realizado por nós - e também o texto do Regimento Comum das Escolas para discussão e debates em toda a rede. Fraternalmente. Paulo Reglus Neves Freire (SÃO PAULO, 1989, p. 03).

Como em seus escritos e em outras práticas que sustentam seu pensamento, ao inaugurar sua gestão, Freire sinaliza o diálogo e a comunicação como instrumentos indispensáveis à gestão de educação pública de caráter popular. O faz, inicialmente, com os docentes, por desejar iniciar sua caminhada partindo de questões cruciais acerca do que é essencial a qualquer projeto de natureza pedagógica: a atividade educativa. Sobre o uso das cartas, parece ter escolhido esta estratégia pelo se caráter afetivo e não apenas formal de uma comunicação 
ou de um ato legal, sobre o qual se tem como única possibilidade o cumprimento. Ao escrever cartas aos docentes, deixa claro que, para além de um gesto de cordialidade, devem ser compreendidas como uma oportunidade de discussão e estudo, para que quem as receba tenha a oportunidade de verdadeiramente expressar seu pensamento.

Nota-se que, já em sua primeira manifestação, Freire anuncia como sua grande meta a criação de uma Educação Pública Popular. Essa expressão merece uma definição de maior profundidade visto que, para muitos, os termos pública e popular podem assumir certa similaridade. Neste sentido:

A Educação Popular está relacionada, em um primeiro momento, com a educação das classes populares. Portanto, tem a ver com uma educação que poderíamos dizer, em uma linguagem mais religiosa, 'educação dos pobres'. Eu não gosto desta expressão, mas tem a ver exatamente com educação dos oprimidos, a educação dos enganados, a educação dos proibidos [...] Educação Popular esteja, primeiro, a serviço dos grupos populares ou dos interesses dos grupos populares, sem que isto signifique a negação dos direitos dos grupos das elites [...]. Mas o grande objetivo da Educação Popular está exatamente em atender os interesses das classes populares que há quinhentos anos estão sendo negados. [...] de um modo mais radical, a Educação Popular significa, para mim, caminhos, isto é, o caminho no campo do conhecimento e o caminho no campo político, através dos quais amanhã - e aí vem a utopia - as classes populares encontrarem o poder. É isto que significa Educação Popular para mim; o que significa nos anos 1960, o que significa nos anos 1970, o que significa nos anos 1980 e o que significa hoje também (FREIRE, 2018, p. 207-208).

Dessa forma, é possível compreender que a educação popular faz uma opção bastante clara e, ao mesmo tempo, um convite. Mesmo sendo uma educação dos esfarrapados, não exclui a presença dos que não o são, razão pela qual é possível dizer que a Educação Popular incide sobre uma característica marcante da concepção de educação e de gestão de Paulo Freire: o nós. Nota-se que, em sua primeira carta aos docentes, exalta a coletividade como cenário para o fim do silenciamento das classes populares, partindo delas, mas não ignorando a necessidade de que os silenciadores também sejam transformados, como forma de garantia de que o direito a dizer a palavra seja concretizado.

O diálogo como antítese do silenciamento é marca inexorável da consolidação de uma Educação Popular e é elemento fundante da gestão de uma escola que a queira materializar. O protagonismo do diálogo é fundamental, uma vez que: 
Não é no silêncio que os homens se fazem, mas na palavra, no trabalho, na ação-reflexão. Mas, se dizer a palavra verdadeira, que é trabalho, que é práxis, é transformar o mundo, dizer a palavra não é privilégio de alguns homens, mas direito de todos os homens. Precisamente por isto, ninguém pode dizer a palavra verdadeira sozinho, ou dizê-la para os outros, num ato de prescrição, com o qual rouba a palavra aos demais. O diálogo é este encontro dos homens, mediatizados pelo mundo, para pronunciá-lo, não se esgotando, portanto, na relação eu-tu (FREIRE, 1987, p. 108-109).

Nesse sentido, a prática dialógica, no contexto da gestão democrática da escola, pautada na participação popular efetiva, será concretamente alcançada diante da dicção de todas as palavras por parte de quem se sinta provocado a dizer algo. Embora as classes populares sejam prioridade, em contraposição a seu histórico silenciamento, não haverá razão para que as outras classes também não se manifestem, pois, do contrário, haveria séria incoerência diante da necessidade de democratização da escola e de sua gestão. À vista disso, a escola pública e popular se opõe a qualquer injustiça que se possa cometer contra as crianças socialmente mais favorecidas, mas, ao contrário, deseja que as todas as crianças conheçam, também, os saberes acessados pela classe burguesa (FREIRE, 2001).

Outra característica da ação de Freire como gestor é o apreço à liberdade, assim como manifesta em todo o seu pensamento. Aposta firmemente na adesão do coletivo e na prática de gestão como uma ação para a libertação. Com o intuito de não definir unilateralmente os caminhos a seguir, a Secretaria Municipal de Educação de São Paulo afirma que "Não vamos impor ideias, teorias ou métodos, mas vamos lutar, pacientemente, por uma educação como prática da liberdade. Nós acreditamos na liberdade. Queremos bem a ela" (SME, 1989, p. 05). Revela, aqui, ao mencionar "educação" e não "gestão" para a prática da liberdade, sua compreensão do caráter pedagógico da gestão democrática e com participação popular efetiva, no que diz respeito à prática da liberdade. Mais do que preocuparse com a gestão das unidades de ensino, Freire enfatiza o caráter político de sua decisão, quando acredita que ao fazer o coletivo participar da gestão da escola, este perceberá que poderá fazê-lo em outros contextos de sua vida.

A liberdade também é exaltada como único caminho para a consolidação da participação popular no processo de gestão da escola, visto que não há democracia que se sustente em qualquer princípio que a afronte. Não é possível mudar as características da gestão de uma escola por meio de uma portaria, pois, para ele, seria uma tentativa autoritária de democratizar a escola (FREIRE, 2001). Por esta razão, uma gestão que se queira democrática precisa ouvir a mocidade, suas famílias, a sociedade e tantos quantos possam e queiram contribuir. 
A participação popular, com este viés, implica na construção de uma escola que efetivamente represente a pluralidade de interesses emergentes desta participação. Assim, de acordo com a Secretaria Municipal de Educação de São Paulo:

\begin{abstract}
Uma escola pública popular não é apenas aquela à qual todos têm acesso, mas aquela de cuja construção todos podem participar, aquela que atende realmente aos interesses populares que são os interesses da maioria; e, portanto, uma escola com uma nova qualidade baseada no compromisso, numa postura solidária, formando a consciência social e democrática. Nela todos os agentes, e não só os professores, possuem papel ativo, dinâmico, experimentando novas formas de aprender, de participar, de ensinar, de trabalhar, de brincar e de festejar (SÃO PAULO, 1989, p. 10).
\end{abstract}

Trata-se de uma proposição que se desnuda de qualquer resquício autoritário e acena para um cenário em que as decisões são tomadas partindo da concretude das demandas, necessidades e utopias do coletivo que a constitui. Trata-se de uma escola pensada em conformidade com os valores e princípios que, efetivamente, contribuam para a garantia de uma educação significativa e capaz de intervir na realidade em que se encontra. Considerando modelos tradicionais de gestão, pode-se dizer que se está diante de uma prática de mudanças necessárias à uma educação que efetivamente contribua para a construção de um futuro viável em que todos e todas caibam. Esta viabilidade se dá pela participação dos que historicamente forma e são subjugados, como se incapazes de definir seu caminhar, definindo o destino de suas próprias existências.

Neste sentido, já sinaliza a Secretaria Municipal de Educação de São Paulo que "a participação popular na criação da cultura e da educação rompe com a tradição de que só a elite, é competente e sabe quais são as necessidades e interesses de toda a sociedade" (SÃO PAULO, 1989, p. 08). Portanto, a gestão democrática da escola, em uma perspectiva de participação popular, não se limita às decisões acerca do destino de recursos financeiros, mas às múltiplas dimensões da gestão que inexoravelmente tem como enfoque, o pedagógico.

Assim, "participar é bem mais do que, em certos fins de semana, "oferecer" aos pais a oportunidade de, reparando deteriorações, estragos das escolas, fazer as obrigações do próprio Estado" (FREIRE, 2001, p. 127). Participação implica na compreensão da profundidade do sentido de pertencimento, fazendo com que os sujeitos se sintam pertencentes ao coletivo escolar. Na medida em que a participação popular fortalece a democracia no contexto da gestão escolar, a afasta de práticas e tradições autoritárias, elitistas e antidemocráticas e historicamente presentes e consolidadas. 
A participação popular, entretanto, não pode se dar de forma aleatória ou pela simples e voluntária presença em um coletivo. É preciso estabelecer esta participação por meio um espaço que respeite a diversidade de opiniões, críticas e concepções. No caso da gestão escolar, um dos caminhos para isso é o Círculo de Cultura, através do qual é possível estabelecer profundas mudanças nas relações de poder no interior da escola, o que é fundamental para gestão democrática da escola fundada na participação popular.

\section{CÍRCULO DE CULTURA COMO POSSIBILIDADE PARA UMA GESTÃO OUTRA}

Um coletivo popular está carregado de diversidade em seus mais variados sentidos: tradições, saberes, práticas, métodos. Assim, uma gestão pautada na participação popular há de mergulhar em todas as expressões de diversidade individual e coletiva a que chamamos de cultura. O estabelecimento de uma prática de participação por meio da cultura é tão fundamental quanto o acolhimento do próprio princípio da democracia. Sobre cultura é preciso afirmar que é:

\footnotetext{
O papel ativo do homem em sua e com sua realidade. O sentido da mediação que tem a natureza para as relações e comunicações dos homens. A cultura como acrescentamento que o homem faz ao mundo que ele não fez. A cultura como resultado de seu trabalho. De seu esforço criador e recriador. O homem, afinal, no mundo e com o mundo, como sujeito e não como objeto. [...] descobrir-se-ia criticamente agora, como fazedor desse mundo da cultura. Descobriria que ele, como o letrado, ambos têm um ímpeto de criação e recriação. Descobriria que tanto é cultura um boneco de barro feito pelos artistas, seus irmãos do povo, como também é a obra de um grande escultor, de um grande pintor ou músico. Que cultura é a poesia dos poetas letrados do seu país, como também a poesia do seu cancioneiro popular. Que cultura são as formas de comportar-se. Que cultura é toda criação humana (FREIRE, 1963, p. 17).
}

A escola e sua gestão são criações humanas, portanto, constituintes de uma cultura com a qual se relacionam e participação da constituição dos outros elementos da cultura de coletivo em que se encontram. Portanto, ao se pensar em uma gestão que agregue os diferentes sujeitos de um contexto, é imprescindível pensar que esta será uma ação cultural. E como não se pretende impor uma hierarquia de saberes e práticas, é necessário que todas dialoguem numa certa horizontalidade. Nesta perspectiva, surge o chamado Círculo de Cultura, que 
[...] era uma experiência em que você trabalhava com duas, três ou até vinte pessoas, não importava. Aí eu havia aprendido muito com a experiência do SESI. Os projetos dos círculos de cultura do MCP não tinham uma programação feita a priori. A programação vinha de uma consulta aos grupos, quer dizer: os temas a serem debatidos nos círculos de cultura, o grupo que estabelecia. Cabia a nós, como educadores, com o grupo, tratar a temática que o grupo propunha. Mas podíamos acrescentar à temática proposta este ou aquele outro tema que, na Pedagogia do oprimido, chamei de "temas de dobradiça" — assuntos que se inseriam como fundamentais no corpo inteiro da temática, para melhor esclarecer ou iluminar a temática sugerida pelo grupo popular. Porque acontece o seguinte: é que, indiscutivelmente, há uma sabedoria popular, um saber popular que se gera na prática social de que o povo participa, mas, às vezes, o que está faltando é uma compreensão mais solidária dos temas que compõem o conjunto desse saber (FREIRE; BET'TO, 1985, p. 14-15).

Uma gestão escolar dita democrática, fundada na essencialidade da participação popular, não poderá prescindir desta sabedoria que constitui a prática cotidiana do coletivo. Ao contrário, o propósito de uma escola dita popular, é constituir-se parte do contexto daquele coletivo e intervir positivamente sobre ele. É importante reconhecer e compreender isso para identificar a profundidade do sentido da participação popular na tomada de decisão quanto aos rumos que a escola deve tomar. Essa participação garante que a escola se torne um local de libertação, uma vez que, não havendo a participação popular na sua gestão, poderá voltar-se contra o próprio coletivo a que serve. Neste sentido:

Sabemos que não é a educação que modela a sociedade, mas, ao contrário, a sociedade é que modela a educação segundo os interesses dos que detêm o poder. Se é assim, não podemos esperar que a educação seja a alavanca da transformação destes últimos. Seria ingênuo demais pedir à classe dirigente no poder que pusesse em prática um tipo de educação que pode atuar contra ela. Se se permitisse à educação desenvolver-se sem fiscalização política, isto traria infindáveis problemas para os que estão no poder. Mas as autoridades dominantes não permitem que isso aconteça e fiscalizam a educação (FREIRE; SHOR, 1997, p. 49).

Esse alerta é fundamental para que cada membro do coletivo escolar possa perceber o quanto a gestão democrática escolar pode ser desvirtuada ou, até mesmo, corrompida, especialmente no que diz respeito às relações de poder. Os detentores de poder, mais do que os dominados por eles, reconhecem a importância estratégica da escola para a preservação de sua hegemonia. Por isso, contar com eles, e apenas com eles, para a instituição de uma gestão democrática para a escola não é concebível. Neste sentido, o controle da gestão deve ser popular (social), feita, portanto, pelo coletivo, em acordo com suas demandas 
e interesses, sem que os de um se sobreponha aos dos demais. O Círculo de Cultura, em que todos os seus membros são postos em um mesmo patamar, permite uma discussão horizontal, com equidade de oportunidades.

Quem exerce a função de gestão, neste cenário, também necessita reconstituir sua prática e reconsiderar sua função no contexto da instituição escolar. Há que se desfazer da conduta autoritária de modelos convencionais de liderança, geralmente de caráter autoritário. Neste sentido "o máximo que faz a liderança autoritária é o arremedo de democracia com que às vezes procura ouvir a opinião dos professores em torno do programa que já se acha, porém, elaborado" (FREIRE, 1997, p. 72). Assim, o gestor, que no extremo de sua capacidade democratizante apenas convida para referendar suas próprias convicções, não hesitará em ignorar a possibilidade de partilhar momentos decisivos. Dessa forma, o Círculo de Cultura cumprirá também esta tarefa: a de constituir um novo gestor.

As características desse gestor são perceptíveis quando "a autoridade coerentemente democrática está convicta de que a disciplina verdadeira não existe na estagnação, no silêncio, mas no alvoroço dos inquietos, na dúvida que instiga na esperança que desperta" (FREIRE, 1996, p. 104). Assim como o professor democrático, o gestor democrático e democratizador farta-se na diversidade e na inquietude, a qual revela o inconformismo e a mobilidade na incerteza, fundamentais para a construção inovadora de uma escola de todos e para todos.

\section{CONCLUSÃO}

Considerando a preocupação de identificar possíveis contribuições do Círculo de Cultura à participação popular na gestão da educação básica em uma perspectiva democrática, torna-se fundamental reconhecer o necessário protagonismo de Paulo Freire para a discussão. Com sua defesa de uma escola pública popular, propõe que a educação garanta aos estudantes, condições de transformar sua vida e de sua comunidade por meio de sua participação. Com isso, aponta caminhos inéditos para que o futuro da educação e de sua gestão não sejam apenas uma extensão do passado.

Em uma tentativa de exercitar a identificação destas possíveis contribuições, pode-se citar que o Círculo de Cultura, para instituir uma gestão escolar democrática com participação popular, implica em materializar valores como:

a) Comunhão: por meio do círculo de cultura, se estabelece uma real comum-unidade que inspira uma comum-união. Nessa relação, os diferentes atores assumem para si e para os segmentos e instituições que representam a atribuição de buscar a unidade entre os diferentes partindo de suas semelhanças. Assim, a 
unidade se estabelece como uma descoberta constante diante de cada desafio que se apresenta, não visto como um problema da escola, mas uma demanda coletiva, em que todos podem assumir uma parcela de responsabilidade.

b) Iniciativa: o fortalecimento da participação popular na gestão democrática da escola, a partir da necessidade de se buscar soluções, é uma forma de desafiar os atores permanentemente. O desafio é sempre uma forma de provocar, para que haja mobilidade como um processo de inicia-ação. Começar uma nova ação é uma oportunidade de, finalmente, estabelecer uma solução para um problema sobre o qual já se projetaram solução já conhecidas sem sucesso.

c) Reciprocidade: o constante diálogo e a presença efetiva de inúmeros atores de diferentes cenários da comunidade, por meio da participação popular, estabelece uma relação de compromisso multilateral em favor da resolução de problemas que atingem a todos. De tal modo, cria-se um ambiente de colaboração recíproca entre todos, estabelecendo-se um compromisso cooperativo inserindo nos debates, conceitos como integralidade, complexidade e diversidade.

d) Comprometimento: a partir do momento em que se criam relações de reciprocidade entre os agentes participantes do processo, é estabelecido, entre eles, um compromisso. Com-prometer significa que, através da interação, em sentido de comum-união, esta deve estar intimamente ligada com o prometer que cada um deve fazer em relação aos demais. Nesse sentido, uma problemática do cotidiano escolar é também das demais entidades e, por esse motivo, todas devem oferecer sua contribuição, seu questionamento e sua disponibilidade franca em colaborar.

e) Solidariedade: a unidade estabelecida entre os atores que compõem a gestão escolar, não apenas uma junção em torno de um problema e suas soluções. É também um espaço em que se debatem estratégias e ações capazes de intervir positivamente no cotidiano da comunidade. Por meio disto, mesmo não havendo necessariamente um problema ou demanda, é possível estabelecer ações que qualifiquem o viver dos membros da comunidade, fomentando um caráter humano e ético ao fazer das diferentes entidades.

Sendo assim, o Círculo de Cultura revela-se não apenas como um instrumento metodológico de organização da participação popular na gestão escolar, mas como um caminho necessário à escola pública e popular. Por meio dele, se estabelece uma forte relação de pertencimento dos sujeitos ao processo de gestão e em relação à própria instituição. O Círculo de Cultura, nessa perspectiva, é uma notável contribuição de Paulo Freire, não apenas à escola e à sua gestão, mas para o estabelecimento de um novo protagonismo dos sujeitos nos diferentes espaços e tempos sociais. 


\section{REFERÊNCIAS}

BAFFI, Maria Adelia Teixeira. Modalidades de pesquisa: um estudo introdutório. Disponível em: http://usuarios.upf.br/ clovia/pesq_bI/textos/ texto02.pdf. Acesso em:20.mar. 2021.

DEMO, Pedro. Metodologia do conhecimento científico. São Paulo: Atlas, 2000.

FREIRE, Paulo. Pedagogia do compromisso: América Latina e Educação Popular. Org.: Ana Maria de Araújo Freire. São Paulo: Paz e Terra, 2018.

; NOGUEIRA, Adriano. Que fazer: teoria e prática em educação popular. Petrópolis, Rio de janeiro: Vozes, 2011.

- Pedagogia da autonomia: saberes necessários à pratica educativa. 11a Edição, São Paulo: Paz e Terra, 2002.

A educação na cidade. 5a edição, São Paulo: Cortez, 2001

Professora sim, tia não: cartas a quem ousa ensinar. 8 edição. São Paulo: Olho d'água. 1997.

. Pedagogia do Oprimido. $17^{\mathrm{a}}$ ed. Rio de Janeiro: Paz e Terra, 1987

. Educação e Participação Comunitária. In: CASTELLS, Manuel. et al. Novas perspectivas críticas em educação. Porto Alegre: Artes Médicas, 1996. p.53-61.

Conscientização e Alfabetização: uma nova visão do processo. Revista de Cultura da Universidade do Recife. No 4; Abril-Junho, 1963.

; BETTO, Frei. Essa escola chamada vida: depoimentos ao repórter Ricardo Kotscho. São Paulo: Ática, 1985

; SCHOR, Ira. Medo e ousadia: o cotidiano do professor. $7^{\mathrm{a}}$ edição. Rio de Janeiro: Paz e Terra. 1997. 
SÃO PAULO. Secretaria Municipal de Educação de São Paulo. Construindo a Educação Pública e Popular, caderno 22 meses, São Paulo, 1990. Disponível em: http://acervo.paulofreire.org:8080/xmlui/handle/7891/1377 Acesso: 21.mar.2021.

SÃO PAULO. Secretaria Municipal de Educação São Paulo. Aos que fazem Educação Conosco em São Paulo. In: Diário Oficial do município de São Paulo. 34 (021). 1\%/02/1989. Suplemento. Disponível em: http://acervo. paulofreire.org:8080/xmlui/handle/7891/1027. Acesso: 21.mar.2021.

\section{Nilton Bruno Tomelin}

Nilton Bruno Tomelin. Doutorando, pesquisador do Programa de Pós Graduação em Educação da Universidade Regional de Blumenau (FURB), Blumenau, SC, Brasil. E-mail: niltonbt@sed.sc.gov.br

\section{Rita Buzzi Rausch}

Rita Buzzi Rausch. Doutora em Educação, Docente e Pesquisadora na Universidade Regional de Blumenau (FURB), Blumenau, SC, Brasil e na Universidade da Região de Joinville (UNIVILLE), Joinville, SC, Brasil. E-mail: ritabuzzirausch@gmail.com 